disagreed that hydrogen is the main component of stars. She based her theory on painstaking analysis of the large cache of stellar spectra in the Harvard collection. It was informed by the predictions of Indian physicist Meghnad Saha's theory of ionization, which relates the observed spectrum of a stellar atmosphere (assuming it is a gas in thermal equilibrium) to its temperature, pressure and composition.

Her conclusion went against a view widely espoused by prominent astronomers, including Arthur Eddington: that stars are made up of essentially the same elements as Earth (silicon, carbon, iron and so on). In response to this criticism, and because she was anxious to get her results published, Payne downplayed her finding as a possible error. Russell was later credited with the discovery, having reached the same result by different means. Payne's role stayed hidden from the wider scientific consciousness for several decades.

\section{Reaching for the stars}

Moore illuminates Payne's development into a remarkable scientist. Her mother had extensive interests outside the home - a rarity in upper-class Edwardian England. Hours spent in the household's library equipped Payne with a knowledge and appreciation of the classics, music and theatre. After the First World War, although shy, she won over mentors and sponsors to help her study physics at the University of Cambridge (which did not award degrees to women at the time). There, she was influenced by Eddington and atomic physicist Ernest Rutherford.

In 1923, Payne set sail for the United States at Shapley's invitation, having secured funding to become a research scientist at Harvard College Observatory. Shapley promoted her talents, but also exploited her. He encouraged her research and at her request hired Sergei Gaposchkin, a Russian astronomer escaping Europe just before the Second World War, who eventually became her husband. But he paid her poorly, so that she and Gaposchkin could not afford childcare, and their three children were often seen playing at the observatory.

He also kept her low in the professional pecking order, even advising another institution against hiring her to a prominent position. She seems to have accepted this as a fact of life, but I wonder how things would have turned out had she received proper professional recognition earlier. It was only in 1954, after Shapley was replaced as director by Donald Menzel, that she received a reasonable salary. Two years later, at the age of 56 , she was awarded a Harvard professorship.

Payne remained at the observatory until her death in 1979. The friends she amassed read like a who's who of early-twentieth-century physics and astronomy. They included those responsible for pushing the new atom theory (Rutherford, J. J. Thomson) and astronomers who were instrumental, with her, in opening up the astrophysical approach to understanding the Universe and its components (Shapley, Russell, Menzel, Eddington). A reproduction of Payne's portrait in oils now hangs prominently in the lobby of the Harvard-Smithsonian Center for Astrophysics - a belated tribute to her hard work and dedication.

\section{“Payne's role stayed hidden from the wider scientific consciousness for several decades."}

I met Payne in the mid-1970s. I remember her as a stern, chain-smoking presence stalking the halls of the observatory: she scolded me for being late for a meeting (recently arrived from Italy, I regarded being precisely on time as impolite). After reading Moore's well-researched book, I realized that she was a complex figure with whom I can empathize despite being two generations younger and from a different background. A committed scientist and mentor to a new generation, she successfully juggled career and family with a love of the arts and world travel.

Her autobiography (published privately as The Dyer's Hand in 1979, and publicly as Cecilia Payne-Gaposchkin in 1984), is worth a read for its personal view of her multifaceted life and her interaction with observatory colleagues, including the female 'computers' who processed astronomical data. I also recommend for its immediacy her 1968 interview for the American Institute of Physics oral-history programme, conducted by Harvard astronomer and historian Owen Gingerich (see go.nature.com/37nm0vr). It captures her essential briskness and rare ability to talk in complex and nuanced sentences.

Giuseppina Fabbiano is senior astrophysicist at the Center for Astrophysics | Harvard \& Smithsonian in Cambridge, Massachusetts, and head of the Chandra X-ray Center Data Systems Division.

e-mail: gfabbiano@cfa.harvard.edu

\section{Apocalyptic archaeology}

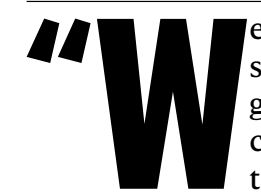
elcome to Armageddon," say Israeli tour guides, as groups from many countries climb the steep incline of the archaeological mound Tel Megiddo, southeast of Haifa and close to Nazareth. Within it are the remains of at least 20 cities, piled up, dating from about 5000 BC to the fourth century BC. Passing through the current gate, the tourists often burst into hymns or prayer.

“Our small group of archaeologists smile tolerantly," recalls Eric Cline in Digging Up Armageddon. They have been digging since before dawn to avoid the heat. A chain-link fence around the excavations jokingly requests: "Please do not feed the archaeologists."

Thus opens an original and lively study that skilfully mixes archaeology with personalities, and politics with culture, science and technology - such as the pioneering 1929 use of a crewless hydrogen balloon to photograph an archaeological site from the air. Dry and detailed analysis of strata and objects mingles with heroic archival excavation of biographical information, personal anecdotes and interpersonal struggles, beginning with the first dig, in 1903-05. The whole benefits from Cline's personal experience. Over ten seasons from 1994 to 2014, starting as a volunteer, he dug in most areas opened up by a Tel Aviv University expedition, rising through the ranks to become co-director with Israel Finkelstein.

\section{"An older stratum revealed fire-blackening and crushed skeletons."}

The book, however, focuses firmly on 1925-39, the most revealing period of excavations. These were run by the Oriental Institute at the University of Chicago, Illinois, under its inaugural director, Egyptologist James Henry Breasted, who coined the phrase 'Fertile Crescent'. Funded by business magnate John D. Rockefeller, the digs were set against the troubled political background of the British Mandate for Palestine, a territory established 


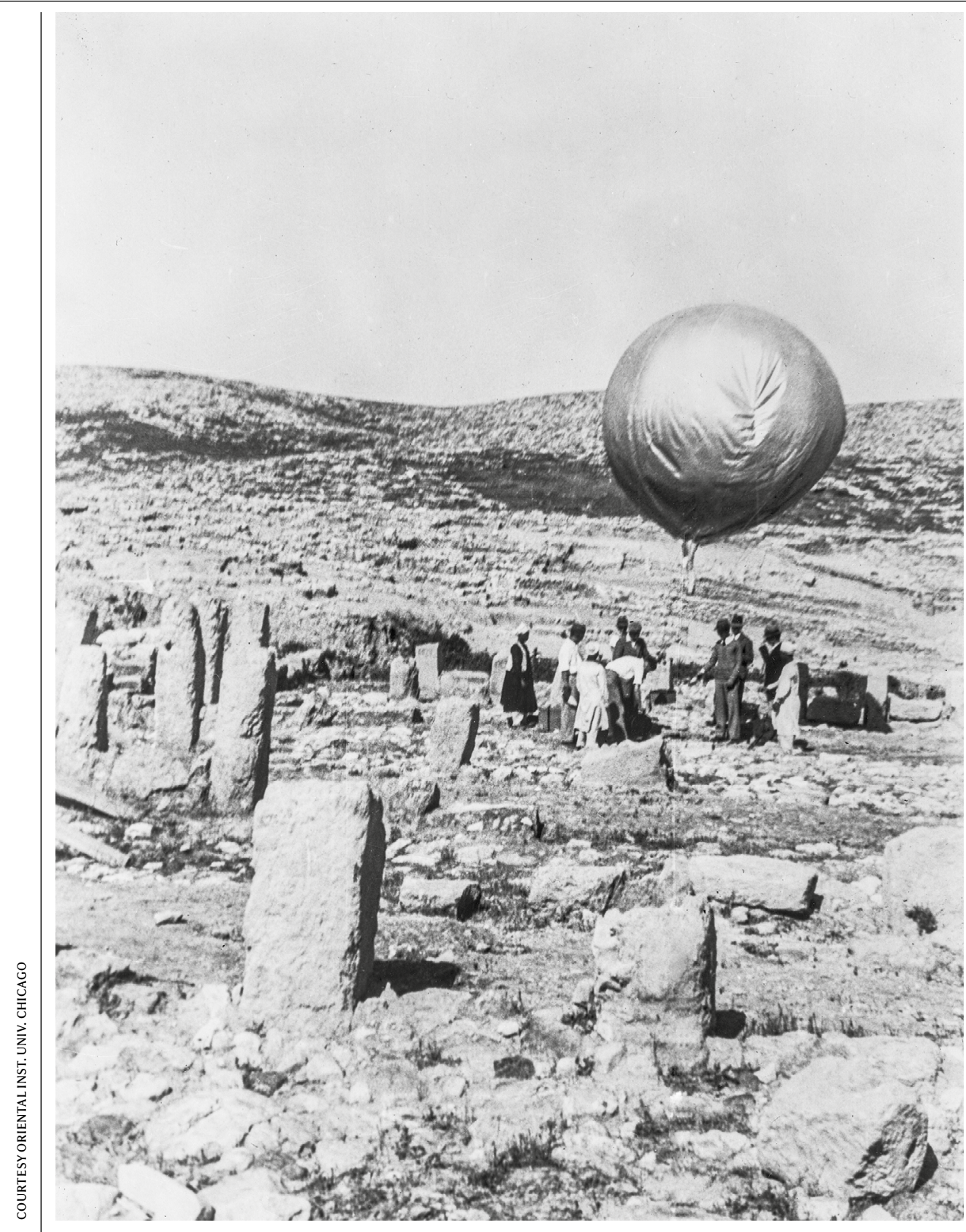

In the 1920s and 1930s, a hydrogen balloon photographed the Megiddo site from the air.

after the defeat of the forces of the Ottoman Empire at the Battle of Megiddo in 1918. Excavations ceased in 1939, when many team members enlisted in the armed forces, "trying to stop the modern world from heading down the road toward a new Armageddon". In 1948, theyear Israel was founded, the expedition's dig house was looted and accidentally burnt down.

\section{Biblical fervour}

Breasted and Rockefeller were fired up by the legend of Armageddon in the Bible, which originally refers to the place as Megiddo, supposedly built by King Solomon in the mid-tenth century BC. Solomon is recorded only in scripture, but Megiddo is mentioned in many other ancient texts, such as the records of Egyptian pharaoh Thutmose III, whose armies captured the city in $1479 \mathrm{BC}$. 'Armageddon' derives from Hebrew HarMegiddo, meaning the mound or expedition's field director cabled Breasted in Chicago: "BELIEVE HAVE FOUND SOLOMONS STABLES". As evidence, the telegram cited the Old Testament, which states that Solomon had 1,400 chariots and 12,000 horsemen stationed in "chariot cities" Hazor, Megiddo and Gezer, and in Jerusalem. The New York Times ran an article that launched Megiddo into "the limelight of biblical archaeology, where it has remained ever since", notes Cline.

But, as so often in archaeology, debate continues. The layout matched stables, but no horse bones have been discovered; and although grain was supposedly found, no analysis of it was ever published. Nor do any inscriptions from Megiddo mention Solomon. Current excavators favour a construction date in the first half of the eighth century $\mathrm{BC}$, during the reign of Jeroboam II; a few think the structure is not a stable, but storehouses or barracks. Overall, Cline cautions: "Solomonic Megiddo has been extremely difficult to find."

Another contentious issue arose from an older stratum that revealed fire-blackening and crushed skeletons, including that of a young girl lying where she had been hit by a falling wall. But what devastated Megiddo in this period? One 1930s excavator postulated a "violent siege and fire by the incoming Philistines, probably circa 1190 BC". The existence of the Philistines is attested by archaeological evidence elsewhere. However, no arrowheads or other weapons were found in or near the Megiddo bodies; nor were there sword marks on the skeletons. In addition, the walls had been misaligned by forces greater than could have been exerted by humans, even humans with battering rams. Moreover, the layer belongs to the tenth century $\mathrm{BC}$, according to twenty-first-century radiocarbon dating.

Cline and others suggest that there was a major earthquake. These certainly occur in the eastern Mediterranean - for example, at Jericho in $31 \mathrm{BC}$ and AD 1927 - as Cline explored in his 2014 book 1177 BC: The Year Civilization Collapsed. However, ancient earthquakes are notoriously hard to authenticate without a contemporary written record. The only certainty, writes Cline, is that the destruction "was an Armageddon for the inhabitants, regardless of whoever or whatever caused it".

Megiddo was finally abandoned just before 300 BC. At least one scholar has proposed that Alexander the Great destroyed the city, "but there is no evidence for such a cinematic finale", jokes Cline - despite the site's long military history. It's more likely that Alexander's army marched past the towering unoccupied mound, unaware of its already historic significance.

Andrew Robinson's numerous books include Earth-Shattering Events: Earthquakes, Nations and Civilization.

e-mail: andrew@andrew-robinson.org 